\title{
Virtual Frontiers: How Online Spaces are Redefining the Value and Viability of Performative Foreign Language Learning
}

\author{
Catherine Van Halsema
}

\begin{abstract}
This paper will seek to contrast the rapidly growing commercial industry of digitally-mediated foreign language education with the gradually diminishing support for foreign language programs in American universities. After first analyzing evidence that justifies the need for foreign language education at the university level, it then digs deeper to locate the characteristics of those most successful online classroom models. It will finally draw on theories of language, teaching, and performativity in an effort to explore how digital spaces have and will shape the relationship between instructor and student and the performance of foreign language learning.
\end{abstract}

\section{Introduction}

If trends in American higher education over the last two decades have shown us anything, it is that foreign language instruction is no longer considered fundamental to a quality education. Shifting economic demands, paired with significant reductions in funding both on the federal and state levels, have caused university administrators across the country to cut foreign language and other humanities programs, and instead focus their resources on the more economically viable areas of science, business, and technology. As a result, foreign language, humanities, and arts programs are put on the defensive, forced to make themselves more cost-effective and technologically relevant, or face reduction or elimination. While online classrooms are in some cases the key to these programs' survival, they are often viewed by these programs as an externally imposed threat to the quality and value of in-person, performance-based learning, thereby causing a catch-22.

Technology itself is not at odds with the spread of foreign language studies, and it needn't be regarded as such in university contexts. While universities are struggling to translate foreign language courses into online offerings, private companies such as Rosetta Stone, VIPKID, Duolingo, and Babbel have helped 
establish an online learning industry that in 2013 alone profited over $\$ 100$ billion (McCue 2014; Nemo 2016). Although the ideological concerns about the commercialization of education are vast (for example, see Ball 2004) and this paper does not contend that they are invalid - the rise of such a market may be considered an unlikely source of hope for the fate of university language programs. First, they indicate that foreign language instruction is not, as university administrative trends might suggest, an undeserving investment of time, energy, and money. Research has shown that a large number of businesses value foreign language ability, cultural sensitivity and awareness, and international experience in their employees - skills that, due to university cuts, many college graduates simply cannot provide (Daniel et al, 2014). Second, the online classroom models that work the best are those that keep teachers in an active, face-to-face relationship with the student. Across the board, incorporating face-to-face instruction with a qualified teacher has accounted for higher profits (Lunden 2016); better retention and completion rates (Khalil \& Ebner 2014); and overall greater satisfaction and success in online courses (Kuo et al. 2013; Muldrow 2013; Straumsheim 2013). Finally - and this is where some creative, out-of-the-box thinking will be required on the part of educators as web-based learning continues to develop - online classrooms provide a new space for exploring the goals of performative foreign language teaching and learning (as defined in Prendergast 2008, drawn from Schechner 1988/2003, 1993 \& 2002, and McKenzie 2001). Because online classrooms are not bound to any physical location and can be accessed from anywhere (and often at any time), they enable entirely new, more diverse groups of students to participate and interact with each other. They also serve as a reflection of the way technology has influenced communication in general. In addition, the lack of a physical classroom to contextualize the learning process reaffirms and reshapes the embodied relationship between instructor and student as individual, collaborating subjects of language and culture. The instructor and the student, in a way, 'become' the classroom together. Online classrooms are not inherently antithetical to performance; on the contrary, if used correctly, they have the potential to establish a new layer for understanding performative learning. The prevalence of online spaces provides a new opportunity for uncovering the underlying principles of critical performance pedagogy (CPP) that remain at play across a variety of learning environments. Whether educators choose to respond to the circumstances that are molding the future of foreign language education by taking advantage of online spaces will be decisive for re-asserting the necessity and benefit of foreign language programs.

\section{Foreign language education: A worthy investment}

When President Eisenhower and the United States Congress enacted the National Defense Education Act (NDEA) into law in 1958, they did so in large part as a response to scientific and technological advances in the Soviet Union, 
particularly the 1957 launch of the world's first artificial satellite, Sputnik I. The Soviet Union's success with Sputnik represented "a blow to American Pride" (Flemming 1960: 134), as it was a clear indication of the shortcomings in the American educational system that they hoped to address. In explaining the importance of the NDEA, former Secretary of Health, Education, and Welfare Arthur S. Flemming cited the study of sciences, foreign languages, and technology as key to "[enriching] personal life, [strengthening] resistance to totalitarianism, and [enhancing] the quality of American leadership on the international scene" (ibid. 132). In the decades following the NDEA, language and communication acted as primary drivers of technological advancement; the need for efficient communication between scientists pushed our modern-day internet to development beyond just a military technology. Learning foreign languages and cultures was a vital partner to science as the world became even more interconnected as an "intricate network of diverse but related interests, each dependent on all others for effective functioning" (ibid. 134). Today, while university foreign language programs are often viewed as unnecessary due to the same technological advancements, science remains a prime destination for university funds.

University programs in business administration have also flourished, especially in the past few decades, as foreign language and other programs in the humanities have diminished. As state and federal funding to universities is cut, administrators are forced to choose which programs to support. The programs bringing in the most private funding - also viewed as those leading directly to employment - such as business and the sciences, are often the ones that survive, thereby perpetuating a policy of exclusion of the humanities and other 'less profitable' disciplines. Business administration has become the top degree program in the country with regard to the number of degrees conferred annually; indeed, the number of business degrees conferred in the United States has increased by nearly 38\% since the year 2000 (U.S. Department of Education 2016). In contrast, over only the last five years the Modern Language Association has estimated that enrollment in foreign language programs has decreased by nearly 7\% (Goldberg et al. 2015). This drop contrasts with the more optimistic MLA survey done in 2009 that had showed steady enrollment and increasingly diverse language course offerings (Lusin 2012). But as these numbers and statistics grow, and foreign language studies and the humanities are gradually edged out in the interest of more streamlined business or science curricula, the real-world needs of corporations particularly in the United States that seek a larger global market are being left unmet.

The recent decline in foreign language majors should not, however, be conflated with an assumption that foreign languages are somehow no longer important. A 2014 study by Daniel, Kedia, and Xie surveyed over 800 corporate executives in the United States and demonstrated that a significant number of hiring companies not only value foreign language and cultural competency in their employees, but in fact 39\% of firms surveyed believe their business has suffered because the majority of American university graduates seeking 
employment lack these skills (Daniel et al. 2014: 20). Additionally, half of all respondents in the 2014 survey rated foreign language ability to be "of great importance" for their needs - a 30\% increase from a similar study conducted only eleven years prior (Kedia \& Daniel 2003). Daniel et al.'s results indicate a clear need for foreign language to be a basic part of business administration program curricula.

Behind all these statistics is a simple, ironic truth: university-level foreign language programs have been increasingly devalued and discontinued in order to devote more resources to industries which are in turn disadvantaged by the shrinking investment in foreign language education. As a result, both individuals and corporations have begun to seek alternative options for learning these essential skills. 55\% of the firms surveyed by Daniel et al. in 2014 confirmed that they have invested in extra training to promote more intercultural competence in their employees (Daniel et al. 2014: 30); of this $55 \%, 44 \%$ of the firms sought assistance from local or web-based university foreign language programs (ibid. 31). The lack of foreign language instruction at the university level for bachelor's degree-seeking students has been a main contributor to the market success enjoyed by private language enterprises, many of which have established their foundation online in order to maintain low operational costs as well as obtain a wider, more rapidly expanding client base. It is therefore beneficial to consider which of these companies are thriving, and what key characteristics of their design have led to their success.

\section{Different forms of digital learning}

Not all online platforms are created equal. They can range from something as simple and individual as a smartphone app, to an online component of a brick-and-mortar classroom, to a Multiple Online Open Course (MOOC) catering to thousands of students at once. Online classroom styles utilized in universities vary greatly, and it would be impossible to outline the intricacies of each type in this paper. There are three main styles, however, that have taken hold of the commercial online learning industry: MOOCs, one-on-one tutoring, and the flipped classroom. ${ }^{1}$ These three formats most closely correspond to those also being offered by universities, and they provide a helpful context for distinguishing which characteristics will most benefit the future of university foreign language education.

When Advance Learning Interactive Systems ONline (ALISON), commonly considered the first ever MOOC, appeared on the digital learning scene in 2007,

\footnotetext{
1 In 2013, a group called FemTechNet developed what they call a DOCC (Distributed Open Collaborative Course) as a more student-centered, peer-to-peer interactive alternative to MOOCs. While their features also emphasize the collaborative learning that is important to foreign language courses, it is not a model that has been adapted to commercial foreign language teaching, and will therefore not be covered in this paper. For more information, see femtechnet.org/docc or the summative 2016 report on Online Course Report (State of the MOOC 2016).
} 
it was met with mixed reactions from educators, administrators, and students alike (High 2013). It wasn't until 2012 that they achieved wild popularity, with more and more elite universities beginning to take part and a cluster of new MOOC startups being founded, such as Harvard University and Massachusetts Institute of Technology's edX, as well as Coursera (Pappano 2012). Since then they have gone on to exemplify what could on the one hand be considered the future of modern learning, full of possibility, and on the other, the devaluation and mechanization of teaching.

Supporters of MOOCs extol the values of open-access education, the flexibility of being able to participate in a course in one's own timeframe, and the creative nature of the project-based tasks completed within the community of students. Because they are open and online, anyone is allowed to sign up, free of charge; the overwhelming majority of courses have been underwritten, designed, and distributed by qualified and respected professors. These are only a few reasons why MOOCs have come to represent a sliver of hope in a society where higher education is rapidly becoming a luxury many cannot afford; they reinvigorate romantic notions of education as a right and not something to be bought (these popular conceptions are expressed through a variety of channels; for further examples, see Dave Cormier's 2010 video; Heller 2013; or Zhenghao et al 2015).

At the same time, MOOCs also reflect some of the more negatively skewed attitudes that have surfaced about the value and future of teaching. If students can learn entire courses-worth of material on their own time, watching pre-recorded video lectures and working on online projects, does that not render the 'teacher' as an interactive body obsolete? Does 'learning' as a process lose its heart the further mediated students and instructors are from each other? And finally, how can a nearly completely automated learning process retain the same quality of educational value found in a traditional, more physically interactive classroom setting? While MOOCs have helped facilitate a seemingly more open learning experience, they have also become the paradigmatic example of the shortcomings of digital education that belies the actual diverse array of online classroom types.

As foreign languages are decidedly difficult to teach using any kind of a 'one-size-fits-all' approach, even in a real-life classroom, it is no wonder that it took several years before MOOCs began to regularly incorporate foreign language into their course offerings. Learning a foreign language requires constant interaction with others, and regular contact with some form of teacher guiding students through the nuances of meaning and culture; both elements of effective language learning that MOOCs, because of their sheer size and design, are hard-pressed to provide. The one-on-one tutoring format has therefore long been a go-to alternative for individual commercial language learning, and modern technology has only expanded its reach. Foreign language companies which had previously built their business around individual computer-assisted language learning, such as Rosetta Stone, have begun to incorporate the option of engaging with a live tutor, though it is 
still not a required piece of the program. Other web-based companies that provide the channel for tutors and clients to connect, such as Verbling, italki, or Wyzant, do not offer a structured curriculum. While these companies and tutors have enjoyed enormous monetary success (Boorstin 2014), and while the benefits of one-on-one tutoring sessions - student-centered lessons provided in a purely interactive setting - are clear, this format is not a practical model for universities to adopt. The workload and cost of sustaining individual tutors for the hundreds or thousands of students enrolled in university language courses would be simply unfeasible. Additionally, sporadic individual tutoring sessions are not a sufficient replacement or counterpart for a full university language course. Nevertheless, the boom of the online tutoring industry demonstrates the necessity of human interaction to the learning process.

Both MOOCs and one-on-one tutoring platforms on their own fall far short of being an acceptable online model for university language courses to adopt. Thankfully, there is a third possibility that has proved successful commercially as well as in university settings: the flipped classroom. The flipped classroom is a pedagogical model that surfaced in the early 1990s with the work of Alison King's From Sage on the Stage to Guide on the Side (1993), and has since spread to show promise for a variety of subjects at all different levels. It essentially breaks down one 'class' into three distinct stages: first, the individual student prepares for the in-class lesson by watching an informational video or pre-recorded lecture, or reading a text; second, the student participates in class with a teacher, either individually or with a group of students, and applies the concepts from the pre-class video to interactive activities and projects; finally, the student completes some form of follow-up assessment to check their understanding after class. It is based around the principle that students learn best when their instructors are able to actively engage and assist them, rather than spending time introducing new material, and it strives to foster a completely learner-centered environment (Alvarez 2012; Bergmann \& Sams 2012). While university courses in the humanities such as English or philosophy have long applied a similar concept of having students read before class, then using the class for discussion, university language courses are generally not structured this way. Flipped classrooms can be implemented with an 'in-class' portion that takes place either in a traditional classroom or in a completely online setting with face-to-face video conferencing between the student(s) and the instructor; their flexible design lends itself well to larger-scale foreign language teaching in a way that both MOOCs and one-on-one tutoring do not.

Both universities and private companies have seen measurable success with the flipped classroom model. VIPKID, for example, is an English as a Second Language (ESL) teaching company based in China that caters to Chinese children aged 5-12. It has been the leading provider of ESL instruction in China since it was founded in 2013. Despite a plethora of competing ESL companies offering less expensive classes, VIPKID has dominated its market because it is able to offer something that many other companies cannot: an 'authentic' and effective North American educational experience. The completely original 
VIPKID curriculum was developed to reflect U.S. Common Core standards and utilizes a flipped classroom model. They hire exclusively North American native speakers of English, the vast majority of whom are already qualified educators by profession. The enormous monetary success that VIPKID has achieved in only a few short years is indicative of not only how effective a flipped classroom model can be for foreign language teaching, but also of the increasing ability of technology to provide a compelling alternative to in-person instruction. Its success would not be possible if it could not deliver a personal link to real-life teachers, in real time. Cindy Mi, CEO of VIPKID, has recently partnered with professors from Stanford University, Harvard University, and the University of Southern California to create a research institute devoted to "improving the effectiveness of education" and to "developing best practices" of how to provide quality education on a large scale (Elstrom \& Ramli 2016). While VIPKID is only one example of a successful foreign language commercial enterprise, the fact that it - a company whose entire business model depends on being able to digitally connect students with real-life teachers - is collaborating with university leaders on how to best develop web-based language underscores the earlier assertion that university foreign language programs may, in fact, stand to benefit from the examples of well-designed and smartly implemented online learning platforms.

The three largest online education distributors in the United States, Coursera, Udacity, and edX, have all sought to guarantee a certain level of market success by partnering with universities and supplying and hosting course content. Of the three, edX is the only non-profit group. They all offer slightly different iterations of the basic MOOC model to accommodate their respective course offerings, with that of edX bordering most closely on the previously described 'flipped classroom' design. Both Udacity and edX direct their focus solely toward STEM field studies, while Coursera has extended its reach to include the humanities and social sciences ("The Big Three" 2012). One of the biggest practical criticisms of MOOCs in general, separate from being utilized in a university setting, is their astoundingly low completion rate. With no requirement of a financial investment, and without the sense of accountability one might ordinarily have in a traditional class format, it is not altogether unsurprising that the average completion rate of MOOCs hovers around only 7\%, out of tens of thousands of students (Parr 2013). Universities have experienced mixed success with the various models. One particularly illustrative example of the impact the different styles and distributors are having on university classrooms is that of San Jose State University. San Jose State University (SJSU) established a partnership with both Udacity and edX to offer several online math classes in the spring of 2013. After one semester, however, SJSU decided to suspend its relationship with Udacity due to a passing rate that was $23 \%$ lower than the rate in traditional classrooms. Students enrolled in courses offered by edX, however, seemed to fare better than students who were not. The difference, according to SJSU Provost Ellen Junn, is that while Udacity courses operated fully online and were intended to fully replace the in-class experience, the 
material from edX only served as a supplement to in-class instruction (Rivard 2013). Despite operating in different spheres, both edX and VIPKID's 'flipped classroom' demonstrate not only that teachers are fundamentally necessary for quality online education, but also that online classrooms and real-life teachers need not stand in opposition to each other.

The final component, in addition to commercial profit and course completion rates, that demonstrates the importance of a teacher's presence in online classrooms is student satisfaction. In a 2013 study of nearly 300 undergraduate and graduate students enrolled in 11 different online university courses, Kuo et al. found that learner-instructor interaction was the second most significant predictors in student satisfaction with online courses. Learnercontent interaction was the strongest predictor of student satisfaction. Kuo et al. concluded in their study that online courses that are designed to incorporate and support project-based collaborative learning may maximize learner-content interaction. Their findings are in line with earlier studies by An \& Reigeluth (2008) and Woo \& Reeves (2007). The flexibility afforded by flipped classrooms make them particularly adaptable to an online setting (both partially or completely), and allow for increased learner-instructor and learner-content interaction. By intentionally incorporating face-to-face and digital interaction between learners and course material, each other, and their instructors, the online classroom becomes a place of possibility for collaborative meaning-making. While web-based instruction may not be an ideal option for foreign language programs, that does have to entail a learning process devoid of performance and authentic communication.

\section{Performative learning in a digital space}

At first glance, it seems a bit unbelievable: web-based distance classrooms as a space for cultivating personal connections and engaging in a complex performative learning process. But returning to the fundamental underpinnings of critical performative pedagogy (CPP) and more closely examining what it means to have a student-centered classroom will help illuminate those pieces of performativity that are present in online spaces, but often overlooked and underused. If we consider the definition of "teaching as performance in the broadest cultural sense of the word," what it ultimately comes down to is a focus on "efficacy of communication and mutual empathetic understanding." (Prendergast 2008: 1, original emphasis). Foreign language educators strive toward these same goals: authentic communication and an ability to view oneself as one performer within a complex and interconnected global society. The use of process drama in the classroom and the development of CPP have appeared until now to be two of the most genuine attempts at guiding learners in this direction. But to assume that online spaces, because they lack physical proximity of learner and teacher, are inherently incapable of fostering these outcomes is to ignore the ways that learners are affected by the society in which they live. Students today are growing up in a world where technology has not 
only created new opportunities for connection and communication, it has also become an extension of the body performing these actions. If we, as educators, genuinely believe in the value of a student-centered classroom, then we have an obligation to ensure that these classrooms - whether physical or digitally transcendent - are built to reflect and respond to these students' experiences of an increasingly interconnected world.

The designation of an online classroom as a 'performative space' suggests a challenge to the role the body plays in the learning process of both language and culture. The mediated interactions between learner and instructor take on a different sort of bodily significance than they would if the two were in physical proximity to one another. Newton (2014) advocates the importance of physicality, arguing that "[m]uch as performance comes into being by the bodily co-presence of performers and audience, so teaching comes into being by the bodily co-presence of teachers and learners, by their encounters and interactions - their relationship" (abstract). Newton goes on to peel back layers of theory contributing to academic notions of embodied learning, from Descartes to Merleau-Ponty, on to Husserl and McClaren. She traces a history of conceptualizing the body from Cartesian mind/body dualism, to seeing the thinking subject as being intrinsically linked to the world of its existence. People "can act as much upon the world as it can upon us" (ibid.), meaning that all learning is an actively experiential process. Critical Performative Pedagogy finds its center in the idea that "the body itself [is] a place of learning and experience" (Pineau 2002, quoted in Newton 2014). But just because the interaction between an instructor and a learner in an online classroom is mediated, it does not mean that their interaction is completely divorced from an embodied act of learning. There are still two living, breathing actors on either side of the screen, engaging with one another and constructing meaning together. In the example of one VIPKID student, parent Victor Gao noted in an interview:

Of course face-to-face is the most effective method for learning, but kids these days are very computer-friendly so it's very easy for them to pick it up... On the other side of the computer are very experienced teachers. They really know how to deal with these kids and how to get their concentration. (Elstrom \& Ramli 2016)

The more that technology shapes our bodily experience of our world, the more online classrooms and web-based distance learning will fall in line with the performance of learning taking place.

By re-assessing the way the body plays into learning across time and space in an online classroom, it is in turn possible to re-consider the utility of online classrooms as spaces for collaborative, performative learning. So what exactly does 'performance' look like in a digital space? Theories of performance developed primarily by Schechner in the late 1980s through the present day, and picked up by McKenzie in the early 2000s, diversified the way teachers were able to view their personal role in the classroom, and allowed for a more complex interpretation of the student-instructor relationship. 
Schechner theorized a "philosophy of performance... as uniquely situated and context-driven aesthetic/ritualistic forms of experience" (Prendergast 2008: 6). Schechner's theory catalyzed the formation of an entire study of performance that "[allows] us to see many aspects of existence as performances" (ibid. 7, original emphasis). While Schechner's work as a whole was instrumental in establishing performance studies as a discipline in its own right, his categorization of performance as being intrinsically linked to context-driven experiences gave traction to the effort to introduce performance into foreign language classrooms. Schewe (2013: 16) defines the primary goal of foreign language didactics as "[creating] a new approach to teaching and learning, whereby emphasis is placed on forms of aesthetic expression." Pedagogical approaches that foster authentic, context-driven communication between students and between the students and their instructor, such as process drama, have defined the development of foreign language teaching over the last several decades.

McKenzie (2001) developed Schechner's work further, breaking down the concept of performance into three distinct areas: culture, economics, and technology. Most relevant to the discussion of online foreign language classrooms, however, is how McKenzie highlights cultural performance as central to understanding ourselves, seeing ourselves as a piece of a larger culture surrounding us, and, finally, acting as interactive agents of transformation in that culture (McKenzie 2001: 29-54). According to Prendergast (2008; interpreting McKenzie 2001), applying performance theory to pedagogy is key to encouraging young people "to perceive and interpret the world and themselves in it as an interconnected series of performers, spectators, and performances at multiple levels of society" (ibid. 9). Online classrooms, by virtue of their reach and accessibility, provide a new space for students to see, in real time, the way they are connected and positioned within the world. As a participant observer of VIPKID over the last year, I have seen the way that thousands of young English learners are 'transported' to the other side of the world through their teachers everyday; in their lessons and in the preand post-lesson activities, students are challenged to experience the language and culture as both a spectator and performer. The digital space enables students to experience their learning with agency, and see in real-time how their cultural and linguistic backgrounds both differ and relate to what they are learning. Lessons in their flipped classroom model are structured to incorporate a level exchange of ideas and information between student and instructor, with each unit finally culminating in an interactive project that encourages students to teach the instructor about aspects of their own culture, in English. Teachers, in turn, are led to talk about their own personal experiences. While VIPKID's example is unique in that the company is international by design, with students from one country only interacting with teachers from another, recent scholarship suggests that digital classrooms may be fertile ground for cultivating effective intercultural communication.

Hua (2014) defines 'culture' as a "form of sharing among a group of 
people... [that] exists wherever human beings conduct their social life" (Hua 2014: 4). As students' social lives increasingly take place in the digital world, opportunities for intercultural communication grow, not diminish. At the same time, technological advancements in the past several decades have led to a world where neither language or culture can be reliably confined to a certain geographical area. Instead, Hua points out, language learning today now requires an ability to navigate "the worldwide network of the target language" (ibid. 9). Digital classrooms that are also able to provide social interaction - the flipped classroom - are therefore a fitting place to start, because they join together the social and technological components of language and culture in the $21^{\text {st }}$ century. Individual students are better able to confront the course content on their own, speculate critically about elements of their own culture, and apply it to their own interactions with their teachers and classmates in a flipped classroom than they might be in traditional brick and mortar classrooms. In a socially-oriented digital learning space, students are exposed to the target language in a context-driven way that emphasizes the interconnectedness of themselves as people and as a member of a global society.

In addition to more accurately reflecting the world in which many students socialize and communicate, online classrooms may also be key in breaking down some of the common socio-economic barriers found in American higher education today. Not only are they more economically feasible for many students, they also allow students greater flexibility with regard to timing and location. Despite the persistent anxiety that online education might somehow replace traditional classroom education, preliminary studies of Georgia Institute of Technology's (GIT) Online Master of Science degree indicate that the students enrolling in the program are students who otherwise would not have been able to pursue their Master's degree in the first place (Maas 2017). GIT's online program was developed to be a complete equivalent to the in-class instruction. It was created by the same faculty teaching each of the in-person classes and it grades by the same standards. Though GIT's example does not particularly pertain to foreign language classes, the same overall concept applies across disciplines: rather than posing a threat to in-person classrooms, online courses are a tool for expanding the market reach of these subjects. According to journalist D. Frank Smith (2017), "the digital trend is opening the doors of higher learning for a variety of students with different needs and lifestyles than traditional students." Over one-third of all students enrolled in online courses are first-generation college students, and over half are employed full-time during the course (Smith 2017, infographic). These are students who normally would not be on campus, in these courses, engaging in the discussions. Online classrooms have the potential to bring an even wider, more diverse group of students from different socio-economic backgrounds together and put them in relationship with one another. By developing online university foreign language courses using a flipped classroom model, with students at the center, the digital classroom will enhance students' exposure to different perspectives and people, thereby enriching their experience of coming to see themselves as a part of a 
complex interconnected group of players in the world.

\section{Conclusion}

While technology in the classroom is by no means a new phenomenon, it has only been in recent years that educators have had to contend with the possibility of technology as the classroom. Tighter university budgets have compelled administrators to pick and choose programs to support, and either explore more cost-effective options, or cut them altogether. Foreign language programs and the humanities as a whole have been one of the main targets for budget cuts, in order to free up resources for the more 'profitable' areas of business and the STEM fields. As a result, many foreign language departments have had to wrestle with the possibility of offering a portion of their courses online. Given the online course design model, MOOC, that has been used most widely in university settings, it is no wonder that foreign language educators may be skeptical or apprehensive about the change. Online course formats as we know them are notoriously impersonal, isolating, and ineffective.

Throughout the last decade, an entire e-learning industry has emerged as a major player in the field of education; some of its largest companies are geared toward foreign language education. These businesses have innovated new ways of designing fully-online course platforms that both take advantage of vast-reaching internet resources, as well as return a real-life teacher to the classroom. The flipped hybrid classroom style used by businesses such as VIPKID is making its way into universities as well. And though it may not be an ideal design, it is one that adds personal connectivity back into the equation.

For many universities, it is no longer a question of whether their foreign language programs will need to be taught online, it is a matter of when. At the same time, new generations of students are growing up in a world where nearly every form of communication is digital in some manner. Efforts to provide future students with a student-centered learning atmosphere will therefore need to acknowledge and incorporate the importance of technology as a way of communicating and understanding one's position in the world. The lack of a physical classroom reaffirms an egalitarian student-teacher relationship, opens the door for wide-reaching, personally relevant cultural connections, and encourages a performance of learning that transcends time and space. Online spaces, particularly spaces that include the personal element of a real-life instructor, provide an important setting for interacting with students who may feel that the digital world houses their primary form of communication. There is no reason that, as the online learning industry continues to evolve, foreign language educators should be left out of the development process. This calls first and foremost for a more charitable view of the potential benefits web-based learning, particularly the flipped classroom model, might bring to the university setting. It may also mean being ready and willing to reach across disciplines and collaborate on creating a new type of digital classroom - one that could facilitate an even closer point of contact between learners, instructors, and 
relevant content. One thing, however, is clear: Online classrooms are not the end of performative learning; they are just the beginning.

\section{Bibliography}

An, Yun Jo, \& Reigeluth, Charles M. (2008): Problem-based learning in online environments. In: Quarterly Review of Distance Education 9/1, 1-16

Ball, Stephen J. (2004): Education for Sale! The Commodification of Everything? King's Annual Education Lecture. http: //www.asu.edu/educ/epsl/CERU/articles/CERU-0410-253-OWI.pdf [last accessed June 6, 2017]

Boorstin, Julia (2014): High-tech Tutoring: Big Media, Big Start-ups \& Big Money. http://www.cnbc.com/2014/08/29/high-tech-tutoring-bigmedia-big-start-ups-big-money .html [last accessed June 9, 2017]

Cormier, Dave (2010): What is a MOOC? Online video clip. YouTube. YouTube, 8 Dec. 2010. https://www . youtube. com/watch?v=eW3gMGqcZlec [last accessed June 15, 2017]

Daniel, Shirley J.; Xie, Fujiao \& Kedia, Ben L. (2014): 2014 Business Needs for Employees with International Expertise. In: The Future of International and Foreign Language Studies conference, Williamsburg, VA, April 11-13, 2014

Elstrom, Peter \& Ramli, David (2006): If the U.S. Won't Pay Its Teachers, China Will. Bloomberg News.

https://www.bloomberg.com/news/articles/2016-12-19/if-the-u-swon-t-pay-its-teachers-china-will [last accessed June 4, 2017]

Flemming, Arthur S. (1960): The Philosophy and Objectives of the National Defense Education Act. In: The Annals of the American Academy of Political and Social Science 326, 132-138

Heller, Nathan (2013): Laptop U. In: The New Yorker. http://www . newyorker.com/magazine/2013/05/20/laptop-u [last accessed May 13, 2017]

High, Peter (2013): Lessons from the CEO of the First Ever MOOC. Forbes. https://www.forbes.com/sites/peterhigh/2013/12/31/lessons-from-theceo-of-the-first-ever-mooc/\#79b446cc4380 [last accessed June 10, 2017]

Hua, Zhu (2014): Exploring Intercultural Communication: Language in Action. Milton Park: Routledge

Khalil, Hanan \& Ebner, Martin (2014): MOOCs Completion Rates and Possible Methods to Improve Retention - A Literature Review. In: Proceedings of World Conference on Educational Multimedia, Hypermedia and Telecommunications 2014. https://www.researchgate.net/publication/306127713_MOOCs_ completion_rates_and_possible_methods_to_improve_retentionA_literature_review [last accessed May 19, 2017] 
King, Alison (1993): From Sage on the Stage to Guide on the Side. In: College Teaching 41/1, 30-35

Kuo, Yu-Chun; Walker, Andrew E.; Belland, Brian R. \& Schroder, Kerstin E. E. (2013): A Predictive Study of Student Satisfaction in Online Education Programs. In: The International Review of Research in Open and Distributed Learning 14/1.

http://www.irrodl.org/index.php/irrodl/article/view/1338/2416 [last accessed May 20, 2017]

Lunden, Ingrid (2016): VIPKID Nabs \$100M to Link Chinese Kids with Native Speakers to Learn English.

https://techcrunch.com/2016/08/03/vipkid-nabs-100m-to-linkchinese-kids-with-native-speakers-to-learn-english/ [last accessed June 4, 2017]

Maas, Steve (2017): Do Online Courses Increase Access to Education? PBS NewsHour: Making Sen\$e. http://www.pbs.org/newshour/makingsense/online-courses-increase-access-education/ [last accessed June $17,2017]$

McCue, TJ. (2014): Online Learning Industry Poised for \$107 Billion in 2015. Forbes. https://www.forbes.com/sites/tjmccue/2014/08/27/onlinelearning-industry-poised-for-107-billion-in-2015/\#7c775ee87103 [last accessed May 17, 2017]

McKenzie, Jon. (2001): Perform or Else: From Discipline to Performance. London and New York: Routledge

Nemo, John (2016): The \$107 Billion Industry That Nobody's Talking About. https://www.inc.com/john-nemo/the-107-billion-industry-thatnobodys-talking-about.html [last accessed June 4, 2017]

Newton, Deborah (2014): Shifting Perspectives and Collapsing Binaries: Critical Performative Pedagogy in the Performance Studies Classroom. In: Scenario 8/2, 17-11

Prendergast, Monica (2008): Teacher as Performer: Unpacking a Metaphor in Performance Theory and Critical Performative Pedagogy. In: International Journal of Education \& the Arts 9/2, 1-19.

http://www.i jea.org/v9n2/v9n2.pdf [last accessed June 14, 2017]

Rivard, Ry (2013): Udacity Project on 'Pause'. Inside Higher Ed. https : //www.insidehighered.com/news/2013/07/18/citing-disappointingstudent-outcomes-san-jose-state-pauses-work-udacity [last accessed June 4, 2017]

Schewe, Manfred (2013): Taking Stock and Looking Ahead: Drama Pedagogy as a Gateway to a Performative Teaching and Learning Culture. In: Scenario $7 / 1,5-23$

Smith, Frank D. (2017): Who Is the Average Online College Student [\#Infographic]. 
https://edtechmagazine.com/higher/article/2014/05/who-averageonline-college-student-infographic [last accessed June 1, 2017]

State of the MOOC (2016): Online Course Report. http:

//www.onlinecoursereport.com/state-of-the-mooc-2016-a-year-ofmassive-landscape-change-for-massive-open-online-courses/ [last accessed June 17, 2017]

The Big Three, At a Glance (2012). The New York Times. http://www.nytimes.com/2012/11/04/education/edlife/thebig-three-mooc-providers.html [last accessed June 1, 2017]

U.S. Department of Education, National Center for Education Statistics (2016): Digest of Education Statistics, 2015 (NCES 2016-014), Chapter 3

Wan, Tony (2017): The Asian Money Fueling US Edtech Investments. EdSurge. https://www.edsurge.com/news/2017-04-26-the-asian-moneyfueling-us-edtech-investments [last accessed May 17, 2017]

Woo, Younghee \& Reeves, Thomas C. (2007): Meaningful Interaction in Web-Based Learning: A Social Constructivist Interpretation. In: Internet and Higher Education 10/1, 15-25

Zhenghao, Chen; Alcorn, Brandon; Christensen, Gayle; Eriksson, Nicholas; Koller, Daphne \& Emanuel, Ezekiel J. (2015): Who's Benefiting from MOOCs, and Why. In: Harvard Business Review.

https://hbr.org/2015/09/whos-benefiting-from-moocs-and-why [last accessed May 20, 2017] 